\title{
Defining Molecular Initiating Events of Airway Sensory Irritation in Support of Predictive Testing Approaches
}

\author{
Evan A. Frank, Lynne T. Haber, Mary Beth Genter, and Andrew Maier
}

\begin{abstract}
Airway irritant exposures in the workplace cause sensory irritation symptoms or signs such as nose and throat pain, rhinorrhea, cough, and airway obstruction, and are associated with nonallergic airway hyperresponsiveness. Using toxicity data to derive chemical-specific occupational exposure limits (OELs) is a critical step in protecting worker health. Respiratory irritation is one of the most common critical effects cited in risk assessments supporting OEL values. However, toxicity data capturing airway sensory irritation responses are often not available for chemicals requiring assessment, even when occupational exposure scenarios indicate inhalation as a route of exposure. As a result, many existing OELs may be inadequately protective against airway irritant responses. This highlights a need for hazard identification methods that are economical, ethical, and informative for sensory irritation effects. In this review, existing knowledge regarding mechanisms of irritancy in the airway is integrated into a mechanistic event framework that accommodates the chemical diversity of airway irritants. This framework identifies discrete molecular initiating events and outcome modifiers upstream of sensory irritation responses. These include activation of specific receptors by irritant ligands, as well as lipid peroxidation, oxidative stress, rapid saline changes, and membrane-detergent events that initiate neuroexcitatory and inflammatory processes in airway nerves and tissues. The use of an in vitro predictive assay suite to measure these events may allow for a low-cost, medium-throughput option for screening large numbers of chemicals for sensory irritant hazards, thereby indicating data needs necessary for setting OELs.
\end{abstract}

Keywords: airway irritation, in vitro methods, molecular initiating events, sensory irritation

\section{Introduction}

$\mathbf{P}$ ROTECTING PEOPLE FROM health effects of occupational and environmental exposures to airway irritants poses challenges due to the large number of compounds for which there are little or no toxicity data to evaluate sensory irritation effects. This gap is difficult to address using conventional toxicity testing due to the limited feasibility, relatively high cost, and scarcity of assays that actually measure sensory irritation responses after toxicant inhalation. In this review, "irritation" refers specifically to sensory irritation, as opposed to looser definitions that may refer to inflammation or corrosion (also termed cytotoxic irritation or tissue irritation). A glossary of key terms is given in Table 1.

Chemical irritants (acrolein, acetic acid, ammonia, chlorine, diisocyanates, acetic anhydride, aldehydes, nitrogen and sulfur oxides, ozone, many detergents, acids, and many other compounds) are used regularly in a wide variety of workplace scenarios, including manufacturing, cleaning, refining, painting, and construction. Airway irritation causes acute symptoms and clinical signs, including pain responses, rhinorrhea, cough, dyspnea, and bronchospasm. Some exposures, such as to inert dusts, may cause some of these airway effects through nonchemical (i.e., mechanosensory) means, whereas this review concerns irritants acting through a biochemical mode of action.

Chronic airway symptoms and disorders associated with high-level or prolonged exposure to irritants include chronic cough $^{1}$ and rhinitis. ${ }^{2}$ Excessive exposure to irritants induces airway hyper-responsiveness to nonspecific stimuli, with nonallergic asthma (known as irritant-induced, intrinsic, chemical asthma) being the best documented example of this. ${ }^{3-7}$ A severe example of this occurring immediately after highlevel exposures is known as reactive airways dysfunction syndrome (RADS), with reactive upper airways dysfunction syndrome (RUDS) being a related diagnosis. ${ }^{8}$ Airway irritants exacerbate the development and severity of classical asthma. ${ }^{9}$

In occupational settings, airway irritation symptoms can impair work, impact fitness for work, impair one's ability to escape from hazard, and exacerbate coexisting respiratory

Department of Environmental Health, University of Cincinnati College of Medicine, Cincinnati, Ohio. 
conditions. ${ }^{10}$ The widespread prevalence of occupational irritant exposures at irritating concentrations causes decreased economic productivity and increased public health costs through associated adverse outcomes. ${ }^{11-14}$

Preventing unsafe levels of inhalation exposure by establishing occupational exposure limits (OELs) continues to be paramount in addressing public health impacts from occupational toxicants. ${ }^{15}$ For the purposes of deriving OEL values, airway sensory irritation symptoms and signs are considered adverse because they interfere with work and predispose the airway to disease. Existing hazard assessment tools used to identify sensory irritants have many limitations. Inhalation tests using human subjects may be used to determine exposure levels at which chemicals are perceived as irritating, but such test methods are problematic due to high cost, poor standardization, low reproducibility, and high levels of variation in subjectively experienced irritation. ${ }^{16,17}$

Sensory testing in rodents (also known as the Alarie test) identifies the airborne concentration at which chemicals cause a stable $50 \%$ reduction in breathing rate (termed the RD50). These values have shown good correlation with irritancy in humans for some compounds, ${ }^{18}$ but this assay has nonetheless been criticized due to substantial variability and limitations in using the RD50 as a metric for predicting human sensory responses. ${ }^{18,19}$ Moreover, this assay is not cost-effective for high-volume screening of potential irritants, nor is it consistent with the " $3 \mathrm{Rs}$ " in reducing, replacing, or refining the use of animals in research.

Other assays applicable to irritancy include protocols for dermal and eye irritation/corrosion, such as the Draize rabbit eye test or the (in vitro) bovine corneal opacity test. These methods are unable to measure acute nervous system responses, and thus do not capture the sensory irritation potency, although they might reflect corrosion or inflammation.

Because OELs are derived primarily with inhalation exposure in mind, respiratory irritation (including both sensory and tissue irritation/inflammation) is one of the most common critical effects used for establishing OELs. ${ }^{19,20}$ Nonetheless, toxicity data that inform actual sensory irritation are often absent due to the above limitations in cost-effective testing. Many OEL assessments are based on systemic dose-response data from oral-dosing toxicity studies, which is not appropriate for assessing airway irritation as a portal-of-entry effect after inhalation exposure. Even OELs that are based on inhalation data typically reflect exposure levels that cause histopathological lesions of the airway, not sensory irritation responses. These limitations appear to be borne out in worker health. Some epidemiological studies for occupations such as healthcare and cleaning have documented increased odds ratios of irritant-induced asthma incidence associated with irritant exposure levels below established OELs. ${ }^{4,5,7}$

The above challenges call for alternatives to existing hazard assessment tools. In vitro cell culture tools offer many possibilities to accomplish this goal in ways that meet other criteria for efficiency, accessibility, and ethical considerations. The risk assessment field has recently developed a systematic approach for developing applied in vitro risk assessment platforms using adverse outcome pathway (AOP) methodology. AOPs map out the sequence of biological events by which chemical exposures perturb homeostasis, resulting in adverse outcomes. The AOP comprises "key events," which are "change(s) in biological state that (are) both measureable and essential to the progression of the defined biological perturbation leading to a specific adverse outcome.,"21

Key events are connected by scientifically based relationships that allow for inference of the state of downstream events from the "known, measured, or predicted state" of upstream events. This sequence begins with molecular initiating events (MIEs), which are defined as "initial point(s) of chemical interaction on a molecular level that results in a perturbation" that initiates the AOP. AOPs have been used to guide the use of in vitro and in silico models that measure or model key events, and thus predict adverse effects as mediated through the AOP. While the current effort described in this article does not seek to establish a canonical AOP according to Organization for Economic Cooperation and Development guidelines, ${ }^{21}$ it uses the AOP conceptual framework to identify the MIEs that underpin sensory irritation responses, and explores ways these MIEs could be measured in vitro to support identification of airway irritation hazards in chemical risk assessments.

\section{Overview of Event Pathways in Irritant Toxicity}

Sensory irritants are chemically diverse and may induce adverse effects in different target cells through multiple MIEs. Broadly, these MIEs include both sensing of irritants by receptors and perturbations caused by intrinsic toxicity or reactivity of the irritant compounds themselves. The MIEs of airway irritation initiate two subsequent pathways of toxicity, in neurons innervating the airway and in epithelium lining the airway, respectively. Extensive crosstalk between these pathways continuously modifies irritation symptoms in response to irritant exposure.

Sensory irritation symptoms after exposure to inhaled irritants are mediated by the stimulation of nociceptive (painsensing) neurons of the trigeminal, glossopharyngeal, and vagus nerves, which innervate the nasal cavity, pharynx, and conducting airways, respectively. ${ }^{22}$ Irritation symptoms and signs caused by irritant exposure in the nasal cavity and nasopharynx include rhinorrhea, sneeze, and dyspnea. ${ }^{23}$ Irritation symptoms and signs resulting from lower airway exposure include cough, airway obstruction (bronchospasm), and mucus secretion. ${ }^{24}$ Collectively, these symptoms and signs constitute sensory irritation responses of the airway. Denervation of airway tissue abolishes these responses to irritants, indicating the importance of neurons as the cells hosting the mechanisms making up this pathway. ${ }^{25,26}$

Nociceptive neurons are distributed throughout the airway basal epithelium and are exposed to inhaled irritants through processes that extend to the apical epithelium. ${ }^{27,28}$ Neurons induce symptoms of irritation when action potentials are generated secondary to calcium influx and transmembrane voltage loss at the site of irritant exposure. ${ }^{29}$ Neuronal transmembrane voltage is determined by the concentrations of cations and anions $\left(\mathrm{Na}^{+}, \mathrm{K}^{+}, \mathrm{Ca}^{2+}\right.$, and $\left.\mathrm{Cl}^{-}\right)$inside and outside the cell, and is sensitive to irritant exposure through various receptor- and channel-based mechanisms.

Many irritant examples act through one or more members of the transient receptor potential (TRP) family of nonselective transmembrane cation channels, of which TRPA1 and TRPV1 are the most studied members and the most relevant to airway irritation. $^{30-32}$ Other receptors mediating nociceptive nerve excitation include acid-sensing ion receptor channels 
and receptors for inflammatory mediators (lipoxygenase products, prostaglandins, and bradykinin).

Excitation of nerves denotes one distinct pathway of airway response to irritants, wherein the MIEs occur in neurons and the downstream events mediate the generation of action potentials. Irritants also provoke inflammatory responses in airway epithelium, an event pathway wherein target cells are not limited to neurons and include airway epithelial cells, myeloid and lymphoid cells, and mesenchymal cells. Inflammatory events downstream of irritant MIEs include activation of cellular second messengers (inositol triphosphate [IP3] and calcium) and paracrine signaling by cytokines, chemokines, growth factors, and various other molecules. ${ }^{33-37}$

The inflammatory processes caused by irritants have been termed "tissue irritation" by some investigators. ${ }^{38}$ Inflammation of the epithelium is a modifier of the sensory response to irritants by promoting nonspecific hypersensitivity. In this way, these inflammatory responses to irritants are thought to link repeated or high-level irritant exposures with nonallergic rhinitis, irritant asthma/RADS-type disease, and related airway conditions. Inflammatory episodes also have the potential to generate mediators that may directly mediate sensory responses, such as bradykinin. ${ }^{39}$

A major challenge in developing predictive assays for airway irritants is a lack of clarity in how toxicity assays may be used to reflect the multiple MIEs that may lead to an irritation response. Efforts to measure irritancy in vitro using low-cost cell culture methods have used TRP channel activation as a critical endpoint meant to predict irritancy. ${ }^{40-42}$

While activity of TRP channels usually plays a substantial role in irritation responses, affinity for TRP channels is only one aspect of an irritant's potential to elicit symptoms. For example, the chemical warfare agent sulfur mustard can be predicted to cause immediate irritation responses based on molecular structure and activity toward TRPA1. Despite these characteristics, sulfur mustard causes no immediate airway symptoms and instead results in a delayed response (6-24 hours) that includes severe sensory irritation symptoms/signs, presumably through a mode of action that differs from TRPA1 agonists that cause immediate effects. ${ }^{43,44}$ This discrepancy in expected versus observed outcomes reflects that responses to sensory irritants can be mediated by diverse mechanisms that go beyond activity toward a specific receptor.

The challenge we address here is how to develop a testing approach for predicting airway irritancy that is applicable to diverse types of irritants that may initiate effects through a variety of MIEs and cause toxicity through multiple downstream event pathways in different target cells. We hypothesize that this can be done by defining MIEs in a well-supported framework that integrates the initiating mechanisms of diverse classes of irritants and their downstream effects. In vitro toxicology assays offer a wide number of highly specific and costeffective tools that may then be used to measure MIEs as a part of an integrative analysis.

\section{MIEs Induced by Irritant Exposures}

The initial molecular perturbations caused by irritants result in irritation symptoms through one or both of the aforementioned event pathways. One pathway is excitation of airway sensory nerves, which directly causes irritation symptoms.
The other is inflammation of epithelium, which can modify and/or indirectly cause sensory irritation responses. The MIEs discussed here fall into the following categories: (1) activation of nociceptors; (2) peroxidation of membrane lipids; (3) induction of reactive oxygen species (ROS) and oxidative stress; (4) abrupt changes in extracellular saline; (5) phospholipase activation during detergent-membrane interactions.

These events are MIEs in the sense that each is a change directly induced by irritant exposure that can result in sensory irritation symptoms alone or in concert with other events. Specific irritant examples may act through one or more MIE, and some MIEs may take place downstream of others (i.e., lipid peroxidation may occur downstream of ROS). The following text describes the molecular biology surrounding each one of these MIEs in greater detail.

\section{Activation of nociceptors}

The aforementioned TRP cation channels are involved in the elicitation of responses to most irritants. Among the TRP family's many members, TRPA1 ("ankyrin 1") and TRPV1 ("vanilloid 1") are usually considered the most relevant to airway irritancy. TRPV4 and TRPM8 are also present and functional in airway tissue, but the roles of these in the initiation of irritation are less pronounced. Approximately $55 \%$ of rat trigeminal neurons are functionally reactive to TRPV1 agonists, while TRPA1 is expressed by a subset of TRPV1-positive neurons. ${ }^{45}$ Human trigeminal neurons are reported to be similarly organized, with a subset of TRPV1-positive nerves also expressing TRPA $1 .{ }^{46}$

Activation of TRP channels results in transient, localized increases in intracellular calcium and sodium. Sufficient depolarization of the neuronal membrane by cation influx will trigger voltage-gated sodium channels and result in the generation of action potentials that mediate irritation symptoms. Because TRPA1 and TRPV1 are generally expressed on the same neurons, agonists that target TRPV1 can affect neuronal responses to TRPA1 agonists and vice versa. ${ }^{47,48}$ TRPA1 is also expressed by non-nerve airway cells, including epithelial cells, and plays a role in the inflammatory responses of these cells to irritants. ${ }^{34,49}$ TRPV1 is reported to be expressed in non-nerve airway cells, but there has not been a consensus of evidence that TRPV1 plays a functional role outside of sensory neurons. ${ }^{50,51}$

TRPA1 is an oxidant sensor and receptor for diverse irritant examples. TRPA1 activation is a versatile irritant-sensing mechanism, able to sense a wide array of irritants through covalent and allosteric binding events. ${ }^{52,53}$ Classical chemical agonists of TRPA1 include acrolein, allicin, aldehydes, isocyanates, and tear gas compounds. A major mechanism of TRPA1 activation involves oxidation of cysteine residues in the ankyrin repeats of TRPA1's cytoplasmic domain. ${ }^{54,55}$ This reactivity-based sensing mechanism is believed to account for TRPA1's diverse range of agonists.

TRPA1 activation by reactive electrophiles is ablated in mutant receptor models lacking the necessary cysteine residues, ${ }^{55}$ and is further attenuated by excess glutathione. ${ }^{56,57}$ Further data support TRPA1 as a common downstream target for diverse oxidizing species such as peroxides and hypochlorite ${ }^{58,59}$ End products of lipid peroxidation have also been shown to activate the channel. ${ }^{33,60}$ 
TRPA1 may be activated through an alternative mode that does not rely on covalent modification of cysteines and is thought to be mediated by a traditional binding groove. ${ }^{61-63}$ Toluene and $\alpha$-terpineol are examples of nonelectrophilic TRPA1 agonists acting through this mechanism, although it appears that these agonists are considerably less potent than reactive examples. ${ }^{62}$ Point-mutation studies have identified critical residues in TRPA1 mediating the alternative mechanism, but molecular structure-activity relationships are unclear at this time. The sensitivity and gating behavior of TRPA1 may be modulated by phosphorylation and allosteric binding sites, which may be acted upon by second messengers downstream of $\mathrm{G}$ protein-coupled receptor (GPCR) activity. Divalent cations (calcium and sodium) also sensitize the channel in a nonspecific manner. ${ }^{64}$

TRPV1 responds to acids, vanilloids, and other pungent compounds. The TRPV1 channel is best known as the receptor mediating the pungent (spicy) sensation evoked by the vanilloid compound capsaicin. ${ }^{65-67}$ Other agonists include related molecules resiniferatoxin (RTX), olvanil, and arvanil, with RTX being one of the most potent agonists known in humans (and also one of the most potent known inducers of coughing). TRPV1 is structurally similar to TRPA1, with most of the exposed domains projecting into the cytoplasm. Whereas TRPA1 apparently answers a need to recognize diverse species of oxidizers and sense noxious cold, TRPV1 contributes to the sensation of burning heat (where $\mathrm{T}>\sim 43^{\circ} \mathrm{C}$ ) and responds directly to acids and free protons (where $\mathrm{pH}<\sim 5$ ). ${ }^{68}$

In addition to its presence at the plasma membrane, TRPV1 is prevalent at internal cell membranes, including the endoplasmic reticulum and mitochondria. Like TRPA1, TRPV1 is modulated by phosphorylation and allosteric binding events, mostly downstream of GPCR signaling, and is cation-sensitive. TRPV1 is not the only airway sensor for acid exposure, as acid-sensing ion channels (ASICs) also contribute to sensory nerve responses to extracellular protons. ${ }^{68}$

The mechanism of action underlying TRPV1 activation is partially understood. ${ }^{69-71}$ Point-mutation studies to determine functional sites have utilized the rabbit and chicken TRPV1, which are sensitive to heat and protons but not vanilloids. ${ }^{70,72}$ These have shown that, while the binding site for protons is located within the extracellular domains of the channel, the binding pocket for capsaicin is within a transmembrane region of the protein. This region is partially open to the extracellular space, but agonists acting by this mechanism generally possess a lipophilic aliphatic region, and a region of this kind appears to be linked to TRPV1 agonism.

The endogenous role of TRPV1 is not known, but it is thought that the vanilloid binding pocket may have arisen to sense endogenous lipid metabolites arising from inflammation (N-arachidonyldopamine, N-oleoyldopamine, etc.). ${ }^{73}$ The vanilloid binding pocket is also the likely binding site of anandamide, an endogenous cannabinoid and TRPV1 agonist. This explanation of TRPV1's role is consistent with the observation that TRPV1 maintains its heat- and acidsensing role across species, but its sensitivity to vanilloids varies (e.g., chicken and rabbit TRPV1 are capsaicin insensitive). There is also evidence that TRPV1 may be a principal receptor mediating pungency of some detergents and soaps by binding to the aliphatic chains of these compounds. ${ }^{74}$
Accordingly, anionic aliphatic surfactants have been shown to be strong TRPV1 agonists. ${ }^{75}$ TRPV1 activity is potentiated by ethanol, possibly through an allosteric mechanism. ${ }^{7,77}$

ASIC receptors mediate some responses to acids. The ASIC receptors are sodium channels that are widely expressed in sensory nerves and are activated in response to acids. In the airway, ASICs are present in myelinated and unmyelinated nerves projecting to the trachea and larynx, and mediate coughing in response to transient exposure to acids. In comparison with the acid-sensing function of TRPV1, ASICs are activated at a higher $\mathrm{pH}$ and produce a faster, more transient response. TRPV1 and ASIC channels are both activated by protons, but exhibit different gating behaviors and distributions among neurons. ${ }^{78,79}$

\section{Lipid peroxidation and generation of oxidized lipids}

Many irritants are oxidants that react with lipids in membranes. Lipid peroxidation is an MIE that generates oxidized lipid species that can activate TRP channels and promote inflammatory response as downstream events. When downstream receptor activation occurs, TRPA1 is typically the target. ${ }^{59,80,81}$ Because TRPA1 reacts with diverse examples of oxidants, irritants that cause lipid peroxidation may also be direct TRPA1 agonists. Some other chemicals that do not appear to react directly with TRPA1 do appear to generate oxidized lipid species that react with and activate TRPA1.

Ammonia is an example of a common irritant that acts as a weak base in epithelial lining and generates oxidized lipid products that activate TRPA $1,{ }^{82,83}$ and the effects of ozone exposure are similarly thought to activate TRPA1. ${ }^{42}$ Activation of TRPA1 in nociceptors directly mediates sensory irritation symptoms. The products of lipid peroxidation can also activate downstream elements responsive to oxidative stress, including JNK and p38 MAP kinases. ${ }^{84}$ In respiratory epithelial cells, these signaling events promote inflammatory responses.

\section{Generating ROS and oxidative stress}

"Reactive oxygen species" are commonly used to refer to both oxygen-based free radicals and nonradicals that either metabolize to a radical form or otherwise have reactive potential in the biological milieu. These include many nitrogenous molecules ("reactive nitrogen species" or RNS) that may be derived from endogenously produced nitric oxide or environmental toxicants such as nitrogen oxides.

Exposure to irritants such as chlorine gas, ozone, hypochlorite (bleach), or many other examples can generate ROS by reacting with pre-existing oxygen or nitrogen species. ${ }^{85-87}$ Increases in specific species such as superoxide, hydrogen peroxide, and nitric oxide may or may not lead directly to nociceptor activation depending on the circumstances, but induce cellular responses to oxidative stress that indirectly but profoundly affect nociceptor function. The prevalence of ROS and the rate of lipid peroxidation are both factors in the homeostatic balance of oxidative and reductive potential in the cell; hence, these events are linked to some degree.

An increase in oxidative potential beyond the cell's homeostatic range is oxidative stress and activates various signaling pathways, especially the JNK and p38 MAPK 
phosphorylation pathways. Members of the Nf- $\kappa \mathrm{B}$ pathway are also redox sensitive. ${ }^{88}$ Inflammatory events induced by these pathways include expression of cytokines (TNF, CXCL1, IL-8, and pro-IL-1 $\beta$ ) and the generation of prostaglandins through upregulation of cyclooxygenase enzymes. ${ }^{89,90}$ Oxidative stress is also a known prerequisite for maturation of the inflammasome, a holoenzyme responsible for maturation of IL- $1 \beta .{ }^{91}$ Some of these molecules can excite sensory nociceptors directly, while others are better described as sensitizers that can lower the threshold of sensory nerve excitation..$^{39,92,93}$

\section{Abrupt changes in saline tone}

Airway exposure to hypertonic saline causes irritation symptoms. ${ }^{94}$ Hypertonic saline directly activates both myelinated and unmyelinated secretory neurons, plausibly through a mechanism involving membrane cotransporters affected by extracellular chlorine ion concentration. ${ }^{95}$ Rapid changes in saline balance in the airway are MIE-type events affecting sensory nerves, and even distilled water vapor produces a bronchoconstrictive response. Classical nociceptors do not appear to be involved in this pathway. It is not clear whether sensory responses to saline changes are directly due to osmolar effects or disruption of transmembrane voltage, and it may not be useful to make a theoretical distinction as both events are aspects inherent to the same physicochemical change.

\section{Phospholipase activation during detergent-membrane interactions}

Many soap and detergent compounds are demonstrated to be sensory irritants, and occupational exposure to detergent chemicals and mixtures is linked to irritation symptoms. ${ }^{4,96}$ Some irritant detergents (deoxyxcholate, quaternary ammonium) do not appear to act on classical $\mathrm{Ca}^{2+}$-channel nociceptors (e.g., TRPV1) but still activate sensory nerves. ${ }^{75}$ The precise MIE in this case is not known in detail. Primary research is limited, but in vitro data support the hypothesis that detergents induce prostaglandin release from cultured cells. Key mechanisms include extracellular calcium influx and membrane phospholipase activity. ${ }^{97-100}$ This suggests that detergents can cause membrane-localized events that directly activate phospholipases, and can cause inflammation and excitation of nerves through a prostaglandin-mediated pathway. For screening purposes, phospholipase activation is a measurable endpoint in vitro and could plausibly be used to identify irritant hazards acting by way of detergent effects.

\section{Overview of MIEs for diverse chemical classes and their contribution to the initiation of irritation symptoms}

The MIEs described in the previous section are intended to encompass the chemical diversity of airway irritants that are capable of eliciting sensory irritation responses. Table 2 presents groupings of irritants by chemistry and molecular targets demonstrated in the literature. In summary, manifold effects arise from irritant exposure by means of receptor- or stress response-mediated event pathways. A variety of nociceptors provide means for sensing a wide variety of noxious stimuli: reactive toxicants, oxidative damage products, acids, and detergents. Nociceptive nerves are also directly responsive to various metabolites of damage response (bradykinin, prostaglandins, and lipooxygenase products). Oxidation events drive airway irritation in many cases, and oxidative stress is a key mechanism by which irritants can cause toxicity without directly activating a specific nociceptor.

Covalent TRPA1 binding, lipid peroxidation, and ROS/ oxidative stress are separate MIEs-different molecular interactions independently causing outcomes-but they are closely related and much overlap exists among the irritants that act through them. TRPA1 is a receptor specialized in the detection of exogenous oxidizers, sensing either the offending compound itself or oxidized lipids generated by it. Toxic levels of oxidants induce oxidative stress by definition, while many but not all oxidants react readily with membrane lipids. Many, but not all lipid oxidizers react with TRPA1 directly. Some compounds do not react with lipids but do activate TRPA1. Figure 1 offers a visual representation of the overlapping MIEs by which oxidants initiate irritation.

Some sensory irritant compounds require a metabolic step to yield an active form before acting through MIEs. Cytochrome P450 enzymes, secreted in the nasal and airway mucosa, have been demonstrated as a requisite for sensory irritation symptoms caused by styrene and naphthalene in a rodent airway resistance test. ${ }^{101}$ Carbon dioxide, a potent respiratory depressant and a strong sensory irritant at high concentrations, requires conversion to carbonic acid when diffusing into mucosa. ${ }^{102,103}$ For experimentation in vitro, metabolic activation of toxicants is typically achieved through the use of transgenic enzyme expression or metabolically competent cell lines. ${ }^{104}$

\section{Table 1. Glossary of Key Terms}

\begin{tabular}{ll}
\hline $\begin{array}{l}\text { Airway irritation } \\
\text { Sensory irritation }\end{array}$ & $\begin{array}{l}\text { Symptoms and signs, including rhinorrhea, cough, mucus secretion, and airway obstruction } \\
\text { Stimulation of nociceptive nerves experienced as stinging, burning, or painful sensations } \\
\text { and also as symptoms/signs of airway irritation in airway tissues } \\
\text { Chemesthesis } \\
\text { Recognition of offensive chemical stimuli by nervous system, experienced as taste, smells, } \\
\text { and stimuli that are harsh, noxious, or painful } \\
\text { Activation of innate immune responses in tissue in response to harmful stimuli, involving } \\
\text { production of mediators by cells and local recruitment of immune cells accompanied by loss } \\
\text { of vascular tone, acute edema, and decreased pH }\end{array}$ \\
$\begin{array}{l}\text { Often used to denote the inflammatory pathway of tissue responses to irritant exposure } \\
\text { Tissue irritation } \\
\text { Nociceptive }\end{array}$ & $\begin{array}{l}\text { Relating to the sensing of painful or noxious stimuli by the nervous system. Uses: nociceptor } \\
\text { (receptor protein for sensing stimuli); nociceptive neuron or nerve (sensory neurons and nerves } \\
\text { that mediate pain, discomfort, or pungency) }\end{array}$ \\
&
\end{tabular}


FIG. 1. Overlap of oxidation-based MIEs and their downstream pathways. MIEs, molecular initiating events.

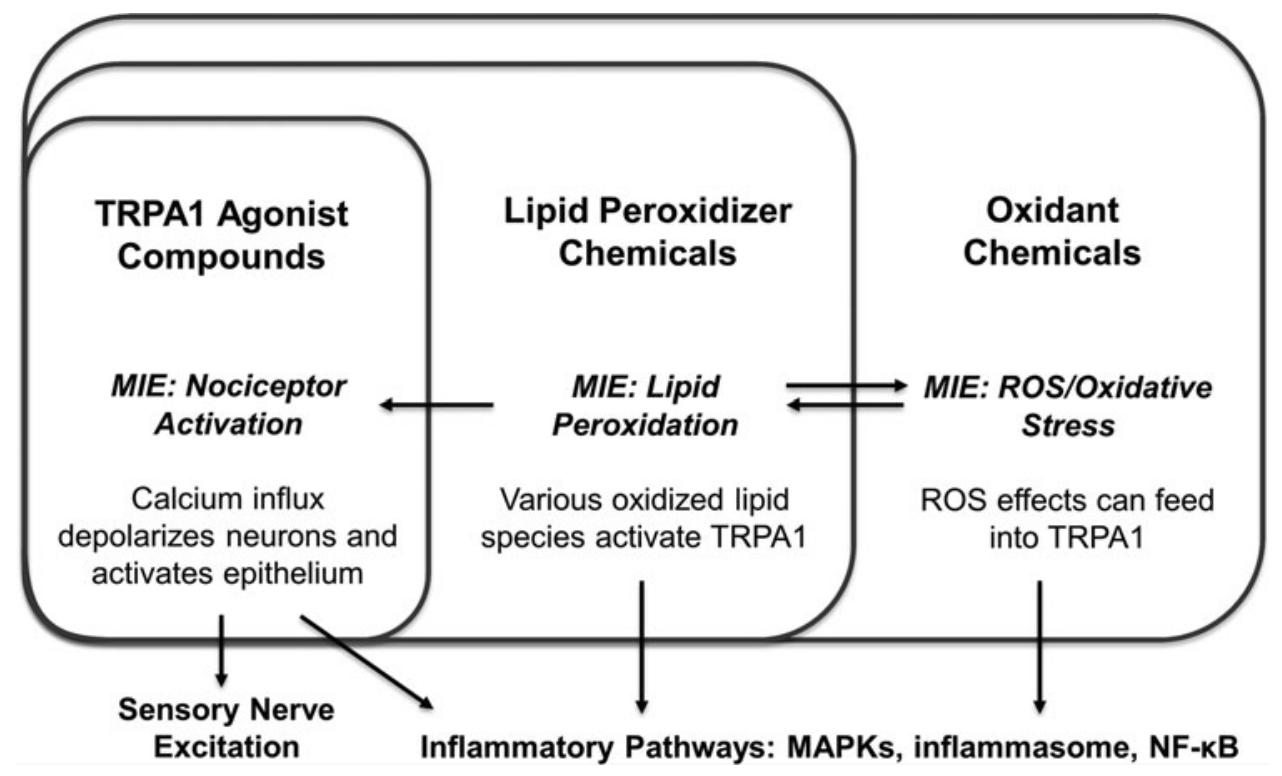

A further consideration of irritancy potential is physicochemical characteristics that determine a given chemical's access to a target tissue. Water-soluble or reactive chemicals are absorbed in the upper respiratory tract, where neurons of the trigeminal nerves are situated, while water-insoluble or inert chemicals (ozone, nitrogen dioxide) reach the lower airways more readily, where they may stimulate the vagus nerve. ${ }^{105}$

In terms of activating sensory nerves, variation in chemical solubility in the mucus biophase has also been shown to account for some of the variability in irritancy among chemicals. ${ }^{106,107}$ This may also hold true for the chemesthetic effects of irritant dusts and particles, with chemosensation being evoked by constituent compounds dissolved from the particle surface. ${ }^{108}$ These considerations are not likely to be reflected in standard in vitro reporter assays, but could be accounted for in an expanded in vitro format incorporating cultured mucus biolayers and simple phase measurements.

\section{Adverse Events and Outcomes Downstream of MIEs}

\section{MIEs lead to calcium signaling events} in airway neurons and epithelial cells

Through direct or indirect activation of nociceptive cation channels, many irritants cause localized calcium transients in target cells. In neurons, calcium is an important part of transmembrane voltage regulation, along with sodium, potassium, and chlorine. ${ }^{109,110}$ Localized membrane depolarizations caused by sufficient calcium influx are rapidly amplified by voltage-gated sodium channels into selfpropagating action potentials that mediate sensory irritation responses through centrally acting mechanisms. TRPV1 and TRPA1 have somewhat different roles in neurons. While nociceptors can mediate calcium-dependent action potentials, overstimulation of TRPV1 induces apoptosis in neurons because of toxicity to mitochondria. TRPA1 overstimulation is not toxic to mitochondria and does not direct neurons into apoptosis. ${ }^{111}$

TRPA1 is functionally expressed by epithelial cells and airway-associated myeloid cells. ${ }^{49}$ Similarly to calcium regulation in neurons, receptor-mediated calcium transients in non-neuronal cells are short lived and tightly localized. Calcium influx sufficient to lead to local calcium accumulation results in widespread activation of calcium-dependent signaling events. These include generation of diacylglycerol and IP3 messengers from phosphatidylinositol bisphosphate mediated by phospholipase C (PLC). ${ }^{37,109}$ The accumulation of cytoplasmic IP3 triggers the release of intracellular calcium stores from the endoplasmic reticulum as well as augmenting the influx of extracellular calcium. ${ }^{112,113}$ In this way, positive feedback mechanisms amplify localized calcium transients into a global calcium increase in the signaling environment of the cytoplasm.

Neighboring epithelial cells can be activated through diffusion of calcium ions and IP3 through gap junctions, and can result in a signaling wave in local epithelium. ${ }^{114}$ Increased calcium triggers release of the subunits of $\mathrm{NF}-\kappa \mathrm{B}$ from their inhibited state through phosphorylation by protein kinase $\mathrm{C}(\mathrm{PKC}){ }^{115,116}$ This enables signaling cascades that result in the expression of cytokines, chemoattractants, and growth factors. These factors modify neuronal responses to irritants and orchestrate inflammation of the airway. Cells in nerve tissue also express inflammatory mediators in a calcium-dependent manner. ${ }^{117}$

\section{MIEs lead to inflammatory events and predispose airway to irritation}

Irritant exposures promote tissue inflammation in the airway through crosstalk between neurogenic and epithelial processes. The signaling etiology of epithelial inflammatory effects is similar in upper and lower airway regions. Nociceptive neurons are distributed through epithelium and participate in irritant-induced inflammation. Capsaicin-reactive neurons are induced by calcium flux and some cytokines to release inflammatory neuropeptides, with the major forms being calcitonin gene-related peptide (CGRP) and substance P (SP). ${ }^{118,119}$

Neuropeptides signal to nerves and other cells through GPCRs, and are an important chemical mechanism for amplifying the effects of sensory irritation. SP sensitizes nerves to 


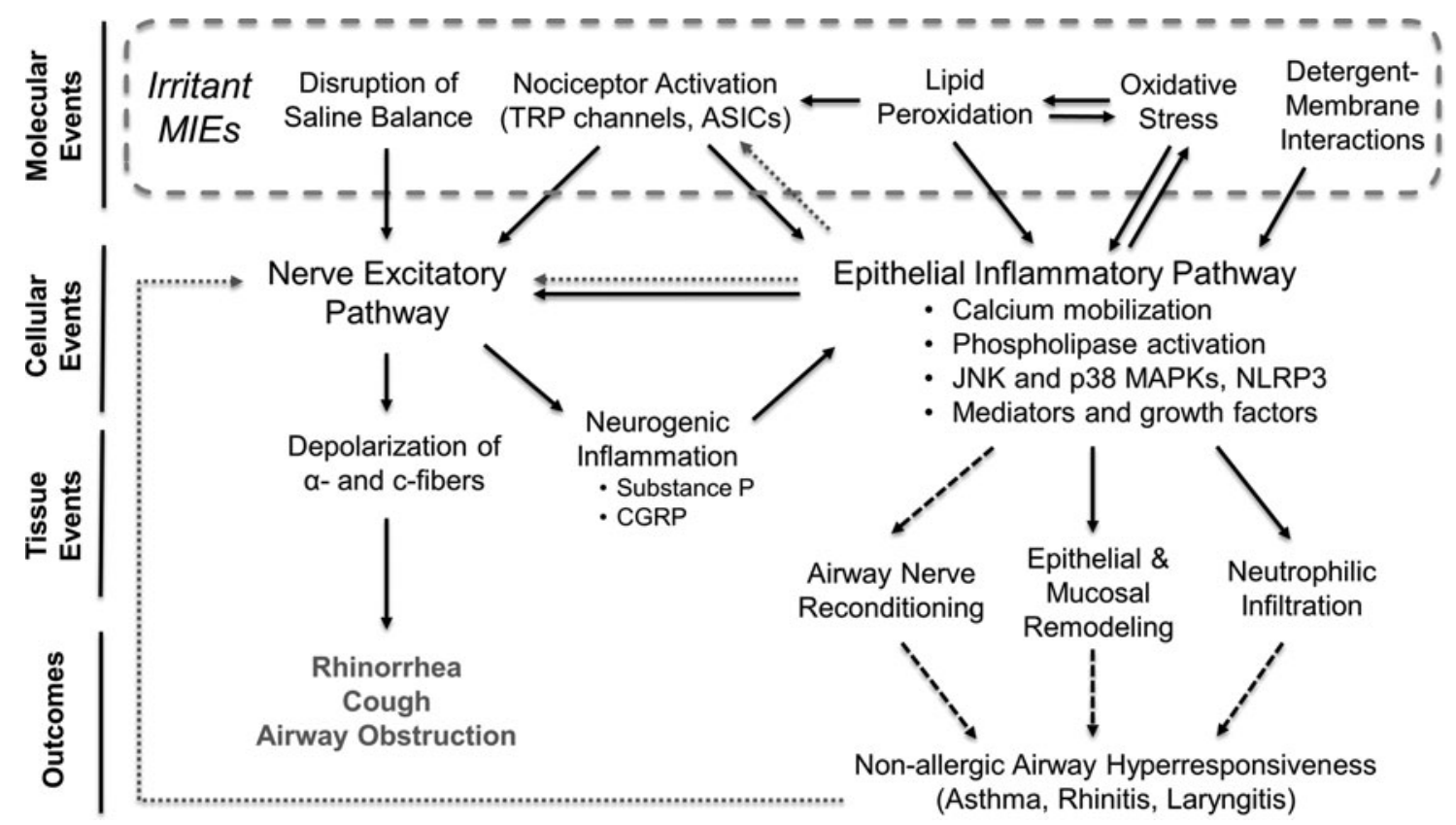

FIG. 2. MIEs and major downstream events of airway irritants. Solid lines: key event relationship; dashed lines: putative key event relationship; dotted lines: sensitizing event relationship.

nociceptive stimulation, playing a positive feedback role that enhances sensory irritation responses. SP causes inflammation in respiratory epithelium by inducing cytokines, and induction of TNF secretion by epithelial cells has been demonstrated in this regard. ${ }^{120}$ Inflammation derived from neuropeptide expression has commonly been referred to as neurogenic inflammation. ${ }^{121-123}$

Signaling through the NF- $\kappa \mathrm{B}$ and MAPK axes enables inflammatory responses in the respiratory epithelium. Perturbations inflicted by irritant exposure lead to calciummobilized signaling and MAPK activation in airway cells of all kinds, and reactive oxidants are especially associated with airway inflammation. Pathophysiology of these responses involves protein exudation, infiltration of neutrophils and other myeloid cells, and stimulation of airway myofibroblasts. Inflammation potentiates sensory irritation symptoms through signaling by cytokines and chemokines. TNF, IL-8, and various chemokines potentiate neuronal responsiveness to irritating stimuli by upregulating and sensitizing TRP channels through PKA- or PKC-mediated phosphorylation. ${ }^{46,117,124-130}$

Oxidants release NF- $\kappa$ B downstream products such as IL8 (CXCL1) from airway cells independently of sensory nerves. ${ }^{34}$ Oxidative stress is a key step in the production of IL- $1 \beta$, a cytokine that potently inflames epithelium and causes release of nerve growth factor (NGF). ${ }^{91}$ NGF is a neurotrophic kinin that promotes neuropeptide release and nerve growth. ${ }^{131,132}$

In summary, inflammation in the epithelium enables and potentiates prolonged sensory responses to irritant exposure. $^{34,93,121,133-136}$ Mutual positive feedback arising from afferent sensory nerve activation and inflammatory processes is thought to be a basis for chronic airway illnesses as a result of prolonged disturbances in regulation of inflammatory processes.

\section{Chronic Adverse Outcomes and Airway Diseases}

Chronic airway conditions downstream of excessive irritant exposure in humans include nonallergic rhinitis, chronic cough, and asthma-like airway hyper-responsiveness. ${ }^{137}$ These conditions are thought to be related by a common etiology involving inflammation of respiratory epithelium in nasopharynx (rhinitis), larynx/throat (laryngitis), and conducting airways (asthma) and aberration of sensory nerve responses in those regions. ${ }^{138}$ Changes in the human respiratory epithelium associated with these conditions include neutrophilia, basement membrane thickening (fibrosis of basal lamina), and migration of mast cells to airway smooth muscle. ${ }^{139-142}$

Whereas lymphocyte and eosinophil infiltration is a classical feature of allergic asthma, neutrophils predominate in chemical-induced airway pathology. ${ }^{142,143}$ The downstream key events of allergic and nonallergic asthma obviously overlap to some degree, and these disease processes appear to synergize because severe asthma cases involve both lymphocytic/eosinophilic and neutrophilic inflammation. ${ }^{144,145}$

Some chemical irritants can also elicit allergic responses as haptens. ${ }^{146}$ The practical difference between allergic and nonallergic airway diseases is that allergic responses are immunologically restricted and occur in response to specific antigens, while nonallergic disease induced by irritant exposure involves nonspecific hypersensitivity to a broad range of stimuli. An AOP has been established for skin sensitization ${ }^{147}$ and may be applicable in situations where hazard assessment of airway irritants as allergic sensitizers is needed. In addition, hazard-based safety assessment tools for asthma arising from irritant exposures have been proposed.

The commonalities between allergic and nonallergic disease pathophysiology in respiratory epithelia support that inflammatory processes are key events in the development of 


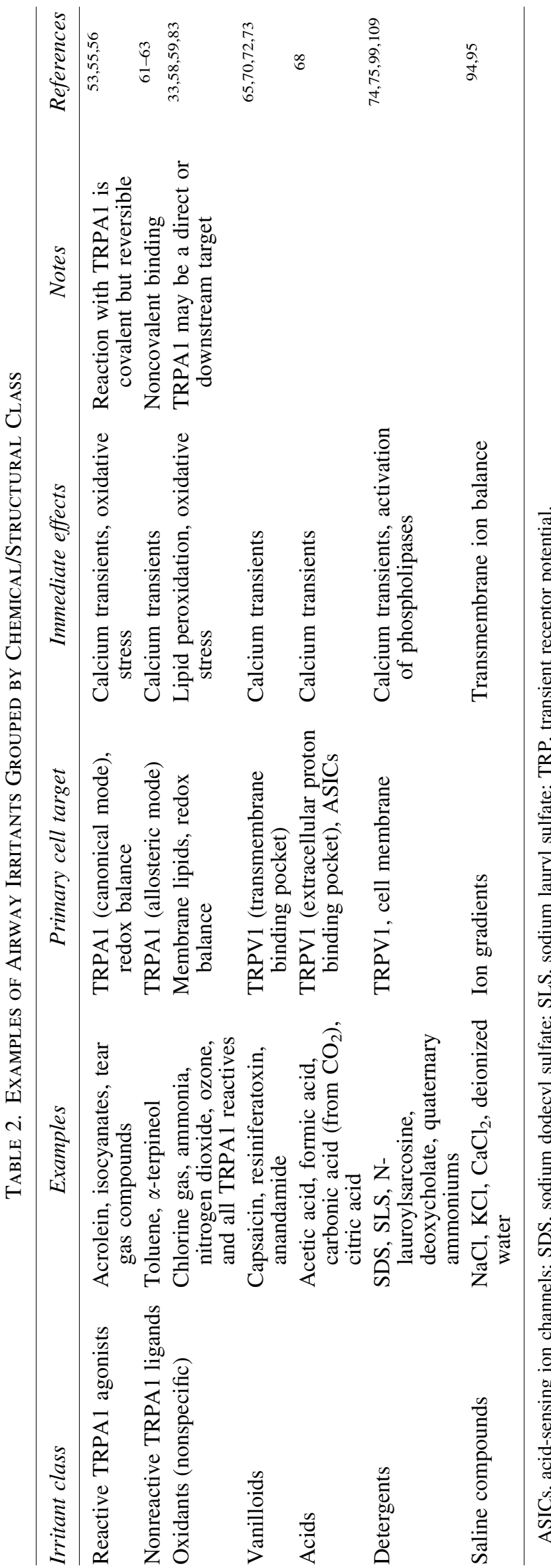

hypersensitivity conditions. These conditions present as exaggerated sensory irritation responses, suggesting aberration of nerve function and structure. In animals exposed to irritants, a decreased density of nociceptive nerve processes was observed in the airway columnar epithelium, while an increased density is found in the airway smooth muscle, lamina propria, basal lamina. ${ }^{148-150}$

Increased density of nociceptive peptide-secreting neurons in bronchial epithelium has been reported in chronic cough and cough-variant asthma patients. ${ }^{151,152} \mathrm{NGF}$, a product of epithelial inflammation, promotes neural growth and is a powerful sensitizer of irritation responses. ${ }^{153,154}$ NGF in human asthmatic airways has been localized to airway epithelial and infiltrating inflammatory cells, highlighting the importance of modeling toxic responses in these cell types when investigating asthma-like responses to airway irritants. ${ }^{155}$

\section{Summary of the MIEs and Downstream Events in Airway Irritation}

Sensory irritation symptoms and signs are mediated by airway nerves in response to MIEs that include activation of nociceptors (vanilloids, acids, electrophilic reactives, and detergents), lipid peroxidation (ammonia, chlorine, nitrogen and sulfur oxides, ozone), and oxidative stress induction (all oxidants), and also deviations from saline homeostasis. Interactions with strong detergents also cause sensory responses. These MIEs cause excitation of airway nociceptive nerves and inflammation of airway epithelium in neuronaland epithelial-borne pathways.

Sustained inflammation arising from crosstalk between neuronal and epithelial pathways is thought to bias airway tissue toward changes that include epithelial and neural remodeling. This manifests as irritant-induced asthma, nonallergic rhinitis, and related conditions such as chronic cough and occupational laryngitis (Fig. 2). A hallmark feature of these chronic conditions is excitation of nociceptive nerves by nonspecific triggers, causing chronic irritation symptoms.

\section{Tools for In Vitro Irritant Toxicology}

\section{Predictive assays for identifying sensory irritants}

This review identifies multiple MIEs by which irritant exposures can be linked to sensory irritation symptoms and related disease. Using in vitro systems to measure a chemical's level of activity through these MIEs may augment hazard assessment by addressing data gaps for compounds lacking sensory irritation data. MIEs were identified based on critical review of the molecular modes of action of known chemical irritants, and we anticipate that a predictive scheme based on these MIEs will be applicable to compounds sharing those modes of action.

OEL values developed in the absence of irritancy data, and sometimes without any inhalation-based data, may be poorly protective against airway irritation effects. Data identifying compounds likely to be airway irritants would allow risk assessors to determine where route-to-route extrapolation of effect data to airway is problematic. Conversely, the use of oral or systemic toxicity data for OELs may be supported, given sufficient data. Along with in vitro genotoxicity and sensitization tests, an assay testing airway irritancy may provide a data package useful in a weight-of-evidence approach 
determining whether additional data (i.e., dose-response inhalation data) are necessary to evaluate risks to the airway as well as serving as a method for prioritizing inhalation testing needs. The wide availability and potential cost-effectiveness of in vitro assays afford laboratories many pre-existing tools that may be used for this purpose. Known irritant compounds with well-characterized human health risk information would need to serve as reference standards in in vitro systems.

In vitro toxicity assays conducted in cultured cell lines have shown some utility in replacing conventional tests that require human subjects or animal use. Currently, there are wellvalidated in vitro assays measuring activity toward TRP channels in the form of basic reporter assays. ${ }^{69,156}$ These use transgenic expression of a receptor of interest in a cell line, usually 293T, that does not express a native version. Calcium influx in cells is measured quantitatively using calcium-binding dyes, and used to measure channel response in nociceptorexpressing cell cultures. ${ }^{110}$ Changes in cellular ROS are measured using a variety of redox-sensitive fluorescent dyes, and various other metrics are commonly used to measure oxidative stress-related events. ${ }^{86,157}$ Well-standardized methods also exist for the quantification of oxidized lipid species. ${ }^{158}$ Several MIEs of irritants are thus testable. Other irritancy factors may be inferred from simple physicochemical traits (e.g., acidity or dissolution of chloride ion).

This review, among others ${ }^{38}$ has identified the importance of epithelial inflammation in the adverse outcomes of irritant exposure. Simple inflammatory changes can be investigated in human epithelial, macrophage, and dendritic cell models.
Measurement of these can include activation of NF- $\kappa \mathrm{B}$ and MAPK pathways, expression of mediators, and phospholipase activation. Activation of membrane phospholipases is a key event by which some irritants, such as detergents, induce effects. Induction of inflammasome assembly, which matures active forms of IL- 1 and related molecules, is a redox-sensitive event that occurs in response to oxidizing irritant compounds. Given the prominent role of oxidative stress and calcium homeostasis in irritant key events, the utility of in vitro assays measuring changes in mitochondrial health and membrane potential as predictive key events in airway irritation responses should be explored.

Table 3 presents a list of in vitro assays that are potentially of use in measuring MIEs and key events of sensory irritation in a predictive design. Moving forward to application of such assays in hazard screening applications will require validation of the assays with negative (nonirritating) controls and known sensory irritants. These known irritants may be selected based on historical example, well-corroborated case studies, as well as existing data from animal and human tests (although these tests have limitations as noted earlier). Predictive application in a more quantitative sense is expected to require combining results from a suite of assays using multivariate analyses.

A variety of tissue culture options exist for staging in vitro measurement of irritant MIEs. These include cell lines of a variety of species (including human) and cell types. The American Type Culture Collection (ATCC) lists several available human airway cell lines derived from normal bronchial epithelium and airway carcinoma cells as well as surrogate tissues such as corneal epithelial cells (Table 4). As noted earlier,

Table 3. In Vitro Assays Applicable to IrRitant Toxicity Screening

\begin{tabular}{|c|c|c|}
\hline Paradigm & Endpoint & Method of detection \\
\hline $\begin{array}{l}\text { Receptor binding } \\
\text { TRP channels } \\
\text { ASICs }\end{array}$ & $\mathrm{Ca}^{2+} \uparrow$ & Quantitative Ca-binding dyes in transgenic reporter cell line \\
\hline ROS & $\begin{array}{l}\text { General ROS } \\
\text { Superoxide } \\
\text { Nitric oxide } \\
\text { Redox-sensitive cellular } \\
\quad \text { responses } \\
\text { DNA oxidation }\end{array}$ & $\begin{array}{l}\mathrm{H}_{2} \text { DCFDA and many fluorogenic redox-sensitive dyes } \\
\text { Redox-sensitive dye (dihydroethidium) } \\
\text { Redox-sensitive dye (DAF-FM diacetate) } \\
\text { Quantification of GSH/GSSG or other redox-sensitive molecules, } \\
\text { or induction of antioxidant response elements } \\
\text { Antibody-based detection of 8-hydroxy-deoxyguanosine }\end{array}$ \\
\hline Lipid peroxidation & $\begin{array}{l}\text { Malondialdehyde } \\
\text { 4-Hydroxynonenal } \\
\text { Global lipid profile }\end{array}$ & $\begin{array}{l}\text { Colorimetric reaction with LMW compound } \\
\text { Antibody detection of } 4 \text {-HNE-protein adducts } \\
\text { Electrospray ionization- or chromatography-coupled tandem mass } \\
\quad \text { spectrometry }\end{array}$ \\
\hline Mitochondrial stress & $\begin{array}{l}\text { Mitochondrial membrane } \\
\text { depolarization } \\
\text { Reduced ATP production }\end{array}$ & $\begin{array}{l}\text { pH-sensitive dye targeted to mitochondria } \\
\text { ATP-binding reporter dye }\end{array}$ \\
\hline Inflammatory response & $\begin{array}{l}\text { Cytokines and mediators } \\
\text { TNF } \\
\text { IL-1 } \beta \\
\text { NGF } \\
\text { IL-8 } \\
\text { Neuropeptides } \\
\text { Others } \\
\text { Inflammasome activation }\end{array}$ & $\begin{array}{l}\text { Antibody-based detection of protein of interest in homogenates } \\
\text { or supernatant }\end{array}$ \\
\hline Cytotoxicity & $\begin{array}{l}\text { Lactate dehydrogenase } \\
\text { Metabolic activity }\end{array}$ & $\begin{array}{l}\text { Colorimetric reaction with LMW compound in supernatant } \\
\text { Tetrazolium dye reduction (MTT assay) }\end{array}$ \\
\hline
\end{tabular}

ATP, adenosine triphosphate; LMW, low-molecular weight; NGF, nerve growth factor; ROS, reactive oxygen species. 
Table 4. Human Airway and Corneal Epithelial Cell Lines Maintained by the American Type Culture Collection

\begin{tabular}{|c|c|c|}
\hline Cell line name & ATCC designation & Tissue of origin \\
\hline HuLa-PC & CRL-3342 & Normal adult larynx \\
\hline HBE4-E6/E7 & CRL-2078 & Normal adult bronchus \\
\hline BEAS-2B & CRL-9609 & Normal bronchus \\
\hline HBE135-E6E7 & CRL-2741 & Normal adult bronchus \\
\hline NL20-TA & CRL-2504 & Normal adult bronchus \\
\hline Calu-3 & HTB-55 & $\begin{array}{l}\text { Bronchial } \\
\text { adenocarcinoma }\end{array}$ \\
\hline 10.014 pRSV-T & CRL-11515 & Normal cornea \\
\hline $\mathrm{HCE}-2$ & CRL-11135 & Normal cornea \\
\hline $2.040 \mathrm{pRSV}-\mathrm{T}$ & CRL-11516 & Normal cornea \\
\hline $\mathrm{FaDu}$ & HTB-43 & $\begin{array}{l}\text { Pharyngeal squamous } \\
\text { carcinoma }\end{array}$ \\
\hline
\end{tabular}

ATCC, American Type Culture Collection.

cell lines used for prediction of irritancy should be demonstrated as metabolically competent to convert proirritants where those irritants require metabolic activation.

Examples of human monocyte/macrophage cells (suitable for monocyte-derived dendritic cell cultures), lymphocytes, and fibroblasts are also available as immortalized lines. All of these options are standardized and widely available, and potentially valuable for identifying irritants that trigger inflammatory responses from these cell types in the airway.

Respiratory epithelial cell lines may be cultured at an airliquid interface (ALI) using specialized culture wells, replicating the physiological conditions of the airway and inducing cells to organize into more realistic epithelial morphology. ${ }^{159}$ The use of ALI to study sensory irritation responses in airway tissue has not been reported, but ALI formats have been used successfully for in vitro models of eye and skin corrosion and irritation tests and are considered ideal for reproducing acute toxicity at the tissue level. ${ }^{160-162}$ ALI cultures may therefore be useful for correlating acute toxicity and inflammatory changes to sensory irritancy among tested compounds, and serve as a bridge to validating results from conventional monocultures. Immortalized bronchial epithelial cells have also been documented to secrete a mucus film when grown in ALI conditions. ${ }^{163}$ This type of test system is valuable for studying interactions of test articles with the mucus biophase.

\section{Potential applications of in vitro irritant toxicology}

In vitro assays designed to measure molecular events initiating effects of airway irritants may be of utility in downstream applications in industrial hygiene and environmental risk assessment. Semiquantitative evaluation of relative potency among suspected irritant chemicals is a feasible outcome from such assays. This would allow for prioritization of chemicals of concern on a basis of relative hazard. Hazard banding strategies are well supported in occupational risk assessment, ${ }^{164}$ and predictive in vitro irritant screening may provide useful inputs into these kinds of methods.

A possible outgrowth of in vitro relative potency assessment would be cumulative risk evaluation. The cheap unit cost of cell culture replicates also allows for expansion of testing throughput necessary for assessing combinations of irritants in a cumulative risk approach. For example, expo- sure to mixed volatile organic irritants is thought to act synergistically in some occupational exposure situations, ${ }^{165}$ but this principle has not been applied in a systematized, semiquantitative format that would produce a readout helpful to assessment of cumulative risk.

In vitro toxicology may also provide useful insights into irritant biology. Advances in global lipidomic profiling allow for the quantification of hundreds of lipid species using tandem mass spectrometry. ${ }^{166}$ Given the prevalence of reactive oxidants among known irritants, specific changes in oxidized lipid profiles may ultimately be linked to irritancy and be used as novel biomarkers for MIEs. Changes in specific lipid metabolites may be used to identify specifics about the initiating oxidation event, such as the toxicant chemical group, membrane of origin (e.g., plasma membrane, mitochondrial, etc.), and endogenous versus exogenous oxidant origination. ${ }^{166}$ Other global profiling approaches include genomics/transcriptomics to explore gene expression in cells in response to exposures, which may help better define downstream stress and inflammatory responses to irritants and how they may differ between irritants of different chemical classes or potencies. ${ }^{167}$

Advances in multidimensional cell culture are bringing in vitro systems into a better position to model inflammatory tissue processes by culturing multiple cell types in arrangements that approximate organ tissue. This approach allows for validation of useful assumptions about how in vitro findings are expected to translate to the whole animal. Airway tissue is amenable to this approach, and the simultaneous culture of airway epithelial cells with macrophages and endothelial cells has had promising success. ${ }^{168}$ Commercially available culture systems also offer biorealistic reproduction of human respiratory epithelium, although these products require human primary cells and cost efficiency is a concern.

Multidimensional culture methodology is also being expanded to organ-on-a-chip microfluidic systems that integrate modeling of circulation and even breathing and airflow. ${ }^{169}$ Although not yet widely available, such systems have demonstrated faithful reproduction of complex signaling events, including extravasation of leukocytes and infiltration into epithelium. These systems can more completely reproduce airway inflammatory processes in vitro and may be useful for demonstrating the validity of measuring proinflammatory MIEs in more practical monocultures.

\section{Conclusion}

In many cases, risk assessments are conducted for inhaled chemicals in the absence of knowledge about respiratory tract response. To address this shortcoming using mediumor high-throughput systems requires defining irritation responses in an event-pathway format. This approach requires consideration of multiple MIEs and downstream pathways occurring in different airway cell types.

In nociceptive neurons, sensory irritation is induced following rapid saline changes, activation of nociceptors, lipid peroxidation, or oxidative stress, and frequently a combination of these. Detergents can also cause chemically mediated irritation responses. MIEs also initiate an inflammatory pathway in the general airway epithelium (epithelial, myeloid, mesenchymal, and neuronal cells). Activation of nerves and inflammation of epithelium are mutually reinforcing, 
and lead to sensory irritation symptoms. Outstanding stimulation of these responses from repeated or high-level exposures to irritants is thought to cause long-term airway changes and airway hypersensitivity diseases.

An in vitro system built from cell-based assays that measure MIEs of irritation may allow sensory irritation risks to be predicted and identify chemicals likely to be irritants. This information would inform data needs for occupational risk assessment of individual chemicals. With additional validation, such a system could be used to evaluate potency of compounds suspected to be sensory irritants. A body of pre-existing irritant examples with known human health effects (and associated irritation no-observed-adverse-effectlevels) could be used as a reference set to assess how well irritancy is captured in such a system.

The use of systematized in vitro tools to minimize or replace more expensive in vivo methods has led to substantial improvements in clinical drug development where in vitro assays used to predict unfavorable biodistribution profiles have significantly reduced the failure rate of clinical trials. ${ }^{170}$ Similarly, the strategic use of in vitro experiments promises to reduce the cost investments necessary to protect human health from occupational exposure to airway irritants.

\section{Acknowledgment}

This research study was supported by the National Institute for Occupational Safety and Health through the Targeted Research Training Program of the University of Cincinnati Education and Research Center Grant \#T42OH008432.

\section{Author Disclosure Statement}

No competing financial interests exist.

\section{References}

1. Brooks SM. Occupational, environmental, and irritantinduced cough. Otolaryngol Clin North Am 2010:43;85-96.

2. Rudmik L, Smith TL. Quality of life in patients with chronic rhinosinusitis. Curr Allergy Asthma Rep 2011:11;247-252.

3. Beach J. Immunologic versus toxicologic mechanisms in airway responses. Occup Med Phila Pa 2000:15;455-470.

4. Medina-Ramón M, Zock JP, Kogevinas M, et al. Asthma, chronic bronchitis, and exposure to irritant agents in occupational domestic cleaning: a nested case-control study. Occup Environ Med 2005:62;598-606.

5. Mirabelli MC, Zock J-P, Plana E, et al. Occupational risk factors for asthma among nurses and related healthcare professionals in an international study. Occup Environ Med 2007:64;474-479.

6. Tarlo SM, Malo J-L. An Official American Thoracic Society Proceedings: work-related asthma and airway diseases. Presentations and discussion from the Fourth Jack Pepys Workshop on Asthma in the Workplace. Ann Am Thorac Soc 2013:10;S17-S24.

7. Vizcaya D, Mirabelli MC, Antó J-M, et al. A workforcebased study of occupational exposures and asthma symptoms in cleaning workers. Occup Environ Med 2011:68;914-919.

8. Brooks SM. Then and now reactive airways dysfunction syndrome. J Occup Environ Med 2016:58;636-637.

9. Henneberger PK, Redlich CA, Callahan DB, et al. An official American Thoracic Society statement: work-exacerbated asthma. Am J Respir Crit Care Med 2011:184;368-378.
10. Chatkin JM, Tarlo SM, Liss G, et al. The outcome of asthma related to workplace irritant exposures: a comparison of irritant-induced asthma and irritant aggravation of asthma. Chest 1999:116;1780-1785.

11. Besen E, Pranksy G. Assessing the relationship between chronic health conditions and productivity loss trajectories. J Occup Environ Med 2014:56;1249-1257.

12. Moscato G, Rampulla C. Costs of occupational asthma and of occupational chronic obstructive pulmonary disease. Curr Opin Allergy Clin Immunol 2003:3;109-114.

13. Petsonk EL. Work-related asthma and implications for the general public. Environ Health Perspect 2002:110;569572.

14. Vandenplas O, Toren K, Blanc PD. Health and socioeconomic impact of work-related asthma. Eur Respir J 2003: 22;689-697.

15. Maier A, Lentz TJ, MacMahon KL, et al. State-of-the-science: the evolution of occupational exposure limit derivation and application. J Occup Environ Hyg 2015:12;S4-S6.

16. Arts JHE, de Heer C, Woutersen RA. Local effects in the respiratory tract: relevance of subjectively measured irritation for setting occupational exposure limits. Int Arch Occup Environ Health 2005:79;283-298.

17. Dalton P. Evaluating the human response to sensory irritation: implications for setting occupational exposure limits. Am Ind Hyg Assoc J 2001:62;723-729.

18. Schaper M. Development of a database for sensory irritants and its use in establishing occupational exposure limits. Am Ind Hyg Assoc J 1993:54;488-544.

19. Bos PM, Busschers M, Arts JH. Evaluation of the sensory irritation test (Alarie test) for the assessment of respiratory tract irritation. J Occup Environ Med 2002:44;968-976.

20. Paustenbach DJ, Gaffney SH. The role of odor and irritation, as well as risk perception, in the setting of occupational exposure limits. Int Arch Occup Environ Health 2005:79;339-342.

21. OECD. Revised Guidance Document on Developing and Assessing Adverse Outcome Pathways. 2nd ed. Paris: Environment Directorate, Organization for Economic Cooperation and Development (OECD); 2017.

22. Scott MRV, Chandler J, Olmstead S, et al. Airway anatomy, physiology, and inflammation. In: The Toxicant Induction of Irritant Asthma, Rhinitis, and Related Conditions. WJ Meggs (ed); pp. 19-61. New York: Springer; 2013.

23. Sant'Ambrogio G, Tsubone H, Sant'Ambrogio FB. Sensory information from the upper airway: role in the control of breathing. Respir Physiol 1995:102;1-16.

24. Lee L-Y. Respiratory sensations evoked by activation of bronchopulmonary C-fibers. Respir Physiol Neurobiol 2009:167;26-35.

25. Duarte AG, Myers AC. Cough reflex in lung transplant recipients. Lung 2012:190;23-27.

26. Szereda-Przestaszewska M, Widdicombe JG. Reflex effects of chemical irritation of the upper airways on the laryngeal lumen in cats. Respir Physiol 1973:18;107-115.

27. Carr MJ, Undem BJ. Bronchopulmonary afferent nerves. Respirology 2003:8;291-301.

28. Lamb JP, Sparrow MP. Three-dimensional mapping of sensory innervation with substance $\mathrm{P}$ in porcine bronchial mucosa: comparison with human airways. Am J Respir Crit Care Med 2002:166;1269-1281.

29. Canning BJ, Spina D. Sensory nerves and airway irritability. In: Sensory Nerves. BJ Canning, D Spina (eds); pp. 139-183. Berlin: Springer Berlin Heidelberg; 2009; vol. 194. 
30. Bessac BF, Jordt S-E. Breathtaking TRP channels: TRPA1 and TRPV1 in airway chemosensation and reflex control. Physiology 2008:23;360-370.

31. Caceres AI, Brackmann M, Elia MD, et al. A sensory neuronal ion channel essential for airway inflammation and hyperreactivity in asthma. Proc Natl Acad Sci U S A 2009:106;9099-9104.

32. Grace MS, Baxter M, Dubuis E, et al. Transient receptor potential (TRP) channels in the airway: role in airway disease. Br J Pharmacol 2014:171;2593-2607.

33. An-Hsuan L, Meng-Han L, Hsin-Kuo K, et al. Lung epithelial TRPA1 transduces the extracellular ROS into transcriptional regulation of lung inflammation induced by cigarette smoke: the role of influxed $\mathrm{Ca}^{2+}$. Mediators Inflamm 2015:2015;1-16.

34. Nassini R, Pedretti P, Moretto N, et al. Transient receptor potential ankyrin 1 channel localized to non-neuronal airway cells promotes non-neurogenic inflammation. PLoS One 2012:7;e42454.

35. Veronesi B, Oortgiesen M, Carter JD, et al. Particulate matter initiates inflammatory cytokine release by activation of capsaicin and acid receptors in a human bronchial epithelial cell line. Toxicol Appl Pharmacol 1999:154;106-115.

36. Chang W, Chen J, Schlueter CF, et al. Common pathways for activation of proinflammatory gene expression by $G$ protein-coupled receptors in primary lung epithelial and endothelial cells. Exp Lung Res 2009:35;324-343.

37. Woodruff ML, Chaban VV, Dirksen ER. Calcium signaling in tracheal epithelial cells. FASEB J 1998:12:A630.

38. Brüning T, Bartsch R, Bolt HM, et al. Sensory irritation as a basis for setting occupational exposure limits. Arch Toxicol 2014:88;1855-1879.

39. Grace M, Birrell MA, Dubuis E, et al. Transient receptor potential channels mediate the tussive response to prostaglandin E2 and bradykinin. Thorax 2012:67;891-900.

40. Bessac BF, Sivula M, von Hehn CA, et al. Transient receptor potential ankyrin 1 antagonists block the noxious effects of toxic industrial isocyanates and tear gases. FASEB J 2009:23;1102-1114.

41. Chung G, Im ST, Kim YH, et al. Activation of transient receptor potential ankyrin 1 by eugenol. Neuroscience 2014: 261;153-160.

42. Taylor-Clark TE, Undem BJ. Ozone activates airway nerves via the selective stimulation of TRPA1 ion channels. J Physiol 2010:588;423-433.

43. Balali-Mood M, Hefazi M. Comparison of early and late toxic effects of sulfur mustard in Iranian veterans. Basic Clin Pharmacol Toxicol 2006:99;273-282.

44. Stenger B, Zehfuss F, Mückter H, et al. Activation of the chemosensing transient receptor potential channel A1 (TRPA1) by alkylating agents. Arch Toxicol 2015:89;1631-1643.

45. Jordt S-E, Bautista DM, Chuang H, et al. Mustard oils and cannabinoids excite sensory nerve fibres through the TRP channel ANKTM1. Nature 2004:427;260-265.

46. Anand U, Otto WR, Facer P, et al. TRPA1 receptor localisation in the human peripheral nervous system and functional studies in cultured human and rat sensory neurons. Neurosci Lett 2008:438;221-227.

47. Akopian AN, Ruparel NB, Jeske NA, et al. Transient receptor potential TRPA1 channel desensitization in sensory neurons is agonist dependent and regulated by TRPV1directed internalization. J Physiol 2007:583;175-193.

48. Ruparel NB, Patwardhan AM, Akopian AN, et al. Homologous and heterologous desensitization of capsaicin and mustard oil responses utilize different cellular pathways in nociceptors. Pain 2008:135;271-279.

49. Fernandes E, Fernandes M, Keeble J. The functions of TRPA1 and TRPV1: moving away from sensory nerves. Br J Pharmacol 2012:166;510-521.

50. Basu S, Srivastava P. Immunological role of neuronal receptor vanilloid receptor 1 expressed on dendritic cells. Proc Natl Acad Sci U S A 2005:102;5120-5125.

51. Ständer S, Moormann C, Schumacher M, et al. Expression of vanilloid receptor subtype 1 in cutaneous sensory nerve fibers, mast cells, and epithelial cells of appendage structures. Exp Dermatol 2004:13;129-139.

52. Nilius B, Appendino G, Owsianik G. The transient receptor potential channel TRPA1: from gene to pathophysiology. Pflugers Arch 2012:464;425-458.

53. Peterlin Z, Chesler A, Firestein S. A painful Trp can be a bonding experience. Neuron 2007:53;635-638.

54. Hinman A, Chuang H, Bautista DM, et al. TRP channel activation by reversible covalent modification. Proc Natl Acad Sci U S A 2006:103;19564-19568.

55. Macpherson LJ, Dubin AE, Evans MJ, et al. Noxious compounds activate TRPA1 ion channels through covalent modification of cysteines. Nature 2007:445;541-545.

56. Nassini R, Gees M, Harrison S, et al. Oxaliplatin elicits mechanical and cold allodynia in rodents via TRPA1 receptor stimulation. PAIN 2011:152;1621-1631.

57. Shapiro D, Deering-Rice CE, Romero EG, et al. Activation of transient receptor potential ankyrin-1 (TRPA1) in lung cells by wood smoke particulate material. Chem Res Toxicol 2013:26;750-758.

58. Andersson DA, Gentry C, Moss S, et al. Transient receptor potential A1 is a sensory receptor for multiple products of oxidative stress. J Neurosci 2008:28;2485-2494.

59. Bessac BF, Sivula M, von Hehn CA, et al. TRPA1 is a major oxidant sensor in murine airway sensory neurons. J Clin Invest 2008:118;1899-1910.

60. Trevisani M, Siemens J, Materazzi S, et al. 4Hydroxynonenal, an endogenous aldehyde, causes pain and neurogenic inflammation through activation of the irritant receptor TRPA1. Proc Natl Acad Sci U S A 2007: 104;13519-13524.

61. Del Prete D, Caprioglio D, Appendino G, et al. Discovery of non-electrophilic capsaicinoid-type TRPA1 ligands. Bioorg Med Chem Lett 2015:25;1009-1011.

62. Richards PM, Johnson EC, Silver WL. Four irritating odorants target the trigeminal chemoreceptor TRPA1. Chemosens Percept 2010:3;190-199.

63. Ryckmans T, Aubdool AA, Bodkin JV, et al. Design and pharmacological evaluation of PF-4840154, a nonelectrophilic reference agonist of the TrpA1 channel. Bioorg Med Chem Lett 2011:21;4857-4859.

64. Doerner JF, Gisselmann G, Hatt H, et al. Transient receptor potential channel A1 is directly gated by calcium ions. J Biol Chem 2007:282;13180-13189.

65. Ho KW, Ward NJ, Calkins DJ, et al. TRPV1: a stress response protein in the central nervous system. Am J Neurodegener Dis 2012:1;1-14.

66. Smutzer G, Devassy RK. Integrating TRPV1 receptor function with capsaicin psychophysics. Adv Pharmacol Sci 2016:2016; e1512457.

67. Szallasi A, Cortright DN, Blum CA, et al. The vanilloid receptor TRPV1: 10 years from channel cloning to antagonist proof-of-concept. Nat Rev Drug Discov 2007:6;357372 . 
68. Faisy C, Planquette B, Naline E, et al. Acid-induced modulation of airway basal tone and contractility: role of acidsensing ion channels (ASICs) and TRPV1 receptor. Life Sci 2007:81;1094-1102.

69. Cao E, Liao M, Cheng Y, et al. TRPV1 structures in distinct conformations reveal activation mechanisms. Nature 2013:504;113-118.

70. Gavva NR, Klionsky L, Qu Y, et al. Molecular determinants of vanilloid sensitivity in TRPV1. J Biol Chem 2004:279;20283-20295.

71. Yang F, Xiao X, Cheng W, et al. Structural mechanism underlying capsaicin binding and activation of the TRPV1 ion channel. Nat Chem Biol 2015:11;518-524.

72. Jordt S-E, Julius D. Molecular basis for species-specific sensitivity to "hot" chili peppers. Cell 2002:108;421-430.

73. Starowicz K, Nigam S, Di Marzo V. Biochemistry and pharmacology of endovanilloids. Pharmacol Ther 2007:114;13-33.

74. Forsby A, Norman KG, Andaloussi-Lilja JE, et al. Using novel in vitro NociOcular assay based on TRPV1 channel activation for prediction of eye sting potential of baby shampoos. Toxicol Sci 2012:129;325-331.

75. Lindegren $\mathrm{H}$, Mogren $\mathrm{H}$, El Andaloussi-Lilja J, et al. Anionic linear aliphatic surfactants activate TRPV1: a possible endpoint for estimation of detergent induced eye nociception? Toxicol In Vitro 2009:23;1472-1476.

76. Trevisani M, Gazzieri D, Benvenuti F, et al. Ethanol causes inflammation in the airways by a neurogenic and TRPV1-dependent mechanism. J Pharmacol Exp Ther 2004:309;1167-1173.

77. Trevisani M, Smart D, Gunthorpe MJ, et al. Ethanol elicits and potentiates nociceptor responses via the vanilloid receptor-1. Nat Neurosci 2002:5;546-551.

78. Gu Q, Lee L-Y. Airway irritation and cough evoked by acid: from human to ion channel. Curr Opin Pharmacol 2011:11;238-247.

79. Lee L-Y, Gu Q, Xu F, et al. Acid-sensing by airway afferent nerves. Pulm Pharmacol Ther 2013:26;491-497.

80. Liu B, Tai Y, Caceres AI, et al. Oxidized phospholipid OxPAPC activates TRPA1 and contributes to chronic inflammatory pain in mice. PLoS One 2016:11:e0165200.

81. Liu B, Escalera J, Balakrishna S, et al. TRPA1 controls inflammation and pruritogen responses in allergic contact dermatitis. FASEB J 2013:27;3549-3563.

82. Dhaka A, Uzzell V, Dubin AE, et al. TRPV1 is activated by both acidic and basic pH. J Neurosci 2009:29;153-158.

83. Digis M. Ammonia toxicity in relation to lipid peroxidation. Res Commun Pharmacol Toxicol 1998:3;76-80.

84. Uchida K, Shiraishi M, Naito Y, et al. Activation of stress signaling pathways by the end product of lipid peroxidation 4-hydroxy-2-nonenal is a potential inducer of intracellular peroxide production. J Biol Chem 1999:274;2234-2242.

85. Baulig A, Garlatti M, Bonvallot V, et al. Involvement of reactive oxygen species in the metabolic pathways triggered by diesel exhaust particles in human airway epithelial cells. Am J Physiol Lung Cell Mol Physiol 2003:285;L671-L679.

86. Halliwell B, Whiteman M. Measuring reactive species and oxidative damage in vivo and in cell culture: how should you do it and what do the results mean? Br J Pharmacol 2004:142;231-255.

87. Taylor-Clark TE. Role of reactive oxygen species and TRP channels in the cough reflex. Cell Calcium 2016:60;155-162.

88. Rahman I, Adcock IM. Oxidative stress and redox regulation of lung inflammation in COPD. Eur Respir J 2006:28; 219-242.
89. Mögel I, Baumann S, Böhme A, et al. The aromatic volatile organic compounds toluene, benzene and styrene induce COX-2 and prostaglandins in human lung epithelial cells via oxidative stress and p38 MAPK activation. Toxicology 2011:289;28-37.

90. Singer CA, Baker KJ, McCaffrey A, et al. p38 MAPK and NF- $\kappa$ B mediate COX- 2 expression in human airway myocytes. Am J Physiol Lung Cell Mol Physiol 2003:285; L1087-L1098.

91. Martinon F. Signaling by ROS drives inflammasome activation. Eur J Immunol 2010:40;616-619.

92. Binshtok AM, Wang H, Zimmermann K, et al. Nociceptors are interleukin-1 $\beta$ sensors. J Neurosci 2008:28;14062-14073.

93. Zhang X-C, Kainz V, Burstein R, et al. Tumor necrosis factor- $\alpha$ induces sensitization of meningeal nociceptors mediated via local COX and p38 MAP kinase actions. Pain 2011:152;140-149.

94. Baraniuk JN, Ali M, Yuta A, et al. Hypertonic saline nasal provocation stimulates nociceptive nerves, substance $\mathrm{P}$ release, and glandular mucous exocytosis in normal humans. Am J Respir Crit Care Med 1999:160;655-662.

95. Taylor-Clark T. Transduction mechanisms in airway sensory nerves. J Appl Physiol 2006:101;950-959.

96. Kreiss K, Gonzalez MG, Conright KL, et al. Respiratory irritation due to carpet shampoo: two outbreaks. Environ Int 1982:8;337-341.

97. Hata Y, Ota S, Terano A, et al. Stimulation of prostaglandin E2 release from cultured rabbit gastric cells by sodium deoxycholate. Prostaglandins 1994:47;423-436.

98. Margheritis E, Castellani B, Magotti P, et al. Bile acid recognition by NAPE-PLD. ACS Chem Biol 2016:11;29082914.

99. Roebrock K, Wolf M, Bovens S, et al. Inhibition of benzalkonium chloride-induced skin inflammation in mice by an indol-1-ylpropan-2-one inhibitor of cytosolic phospholipase A2 $\alpha$. Br J Dermatol 2012:166;306-316.

100. Zhu Y, Hua P, Rafiq S, et al. $\mathrm{Ca}^{2+}$ - and PKC-dependent stimulation of PGE2 synthesis by deoxycholic acid in human colonic fibroblasts. Am J Physiol Gastrointest Liver Physiol 2002:283;G503-G510.

101. Lanosa MJ, Willis DN, Jordt S, et al. Role of metabolic activation and the TRPA1 receptor in the sensory irritation response to styrene and naphthalene. Toxicol Sci 2010: 115;589-595.

102. Jürgens TP, Reetz R, May A. No relevant modulation of TRPV1-mediated trigeminal pain by intranasal carbon dioxide in healthy humans. J Headache Pain 2013:14;33.

103. Tzabazis AZ, Niv SH, Manering NA, et al. Trigeminal antihyperalgesic effect of intranasal carbon dioxide. Life Sci 2010:87;36-41.

104. Garcia-Canton C, Minet E, Anadon A, et al. Metabolic characterization of cell systems used in in vitro toxicology testing: lung cell system BEAS-2B as a working example. Toxicol In Vitro 2013:27;1719-1727.

105. Shusterman D. Toxicology of nasal irritants. Curr Allergy Asthma Rep 2003:3;258-265.

106. Abraham MH, Sanchez-Moreno R, Cain WS. Physicochemical modeling of sensory irritation in humans and experimental animals. In: Toxicology of the Nose and Upper Airways. JB Morris, DJ Shusterman (eds); pp. 376-389. New York: Informa Healthcare; 2010: vol. 30.

107. Abraham MH, Nielsen GD, Alarie Y. The Ferguson principle and an analysis of biological activity of gases and vapors. J Pharm Sci 1994:83;680-688. 
108. Cain WS, Jalowayski AA, Kleinman M, et al. Sensory and associated reactions to mineral dusts: sodium borate, calcium oxide, and calcium sulfate. J Occup Environ Hyg 2004:1;222-236.

109. Berridge MJ, Bootman MD, Roderick HL. Calcium signalling: dynamics, homeostasis and remodelling. Nat Rev Mol Cell Biol 2003:4;517-529.

110. Grienberger C, Konnerth A. Imaging calcium in neurons. Neuron 2012:73;862-885.

111. Stueber T, Eberhardt MJ, Caspi Y, et al. Differential cytotoxicity and intracellular calcium-signalling following activation of the calcium-permeable ion channels TRPV1 and TRPA1. Cell Calcium 2017:68;34-44.

112. Liu L, Simon SA. The influence of removing extracellular $\mathrm{Ca}^{2+}$ in the desensitization responses to capsaicin, zingerone and olvanil in rat trigeminal ganglion neurons. Brain Res 1998:809;246-252.

113. Parekh AB, Putney JW. Store-operated calcium channels. Physiol Rev 2005:85;757-810.

114. Kumar NM, Gilula NB. The gap junction communication channel. Cell 1996:84;381-388.

115. Lilienbaum A, Israël A. From calcium to NF- $\kappa \mathrm{B}$ signaling pathways in neurons. Mol Cell Biol 2003:23;2680-2698.

116. Steffan NM, Bren GD, Frantz B, et al. Regulation of $\mathrm{I} \kappa \mathrm{B}$ alpha phosphorylation by $\mathrm{PKC}$ - and $\mathrm{Ca}(2+)$-dependent signal transduction pathways. J Immunol 1995:155;4685-4691.

117. Qin X, Wan Y, Wang X. CCL2 and CXCL1 trigger calcitonin gene-related peptide release by exciting primary nociceptive neurons. J Neurosci Res 2005:82;51-62.

118. Nakamura Y, Une Y, Miyano K, et al. Activation of transient receptor potential ankyrin 1 evokes nociception through substance $\mathrm{P}$ release from primary sensory neurons. J Neurochem 2012:120;1036-1047.

119. Richardson JD, Vasko MR. Cellular mechanisms of neurogenic inflammation. J Pharmacol Exp Ther 2002:302;839 845.

120. Veronesi B, Carter JD, Devlin RB, et al. Neuropeptides and capsaicin stimulate the release of inflammatory cytokines in a human bronchial epithelial cell line. Neuropeptides 1999:33;447-456.

121. Bascom R, Meggs WJ, Frampton M, et al. Neurogenic inflammation: with additional discussion of central and perceptual integration of nonneurogenic inflammation. Environ Health Perspect 1997:105;531-537.

122. Geppetti P, Nassini R, Materazzi S, et al. The concept of neurogenic inflammation. BJU Int 2008:101;2-6.

123. Veldhuis NA, Poole DP, Grace M, et al. The G proteincoupled receptor-transient receptor potential channel axis: molecular insights for targeting disorders of sensation and inflammation. Pharmacol Rev 2015:67;36-73.

124. Dai Y, Wang S, Tominaga M, et al. Sensitization of TRPA1 by PAR 2 contributes to the sensation of inflammatory pain. J Clin Invest 2007:117;1979-1987.

125. Dong F, Du Y-R, Xie W, et al. Increased function of the TRPV1 channel in small sensory neurons after local inflammation or in vitro exposure to the pro-inflammatory cytokine GRO/KC. Neurosci Bull 2012:28;155-164.

126. Hu Y, Gu Q, Lin R-L, et al. Calcium transient evoked by TRPV1 activators is enhanced by tumor necrosis factor- $\alpha$ in rat pulmonary sensory neurons. Am J Physiol Lung Cell Mol Physiol 2010:299;L483-L492.

127. Lin R-L, Lin Y-J, Geer MJ, et al. Pulmonary chemoreflex responses are potentiated by tumor necrosis factor-alpha in mice. J Appl Physiol 2013:114;1536-1543.
128. Mandadi S, Numazaki M, Tominaga M, et al. Activation of protein kinase $\mathrm{C}$ reverses capsaicin-induced calciumdependent desensitization of TRPV1 ion channels. Cell Calcium 2004:35;471-478.

129. Schmidt M, Dubin AE, Petrus MJ, et al. Nociceptive signals induce trafficking of TRPA1 to the plasma membrane. Neuron 2009:64;498-509.

130. Wang J-G, Strong JA, Xie W, et al. The chemokine CXCL1/growth related oncogene increases sodium currents and neuronal excitability in small diameter sensory neurons. Mol Pain 2008:4;38.

131. Fox AJ, Patel HJ, Barnes PJ, et al. Release of nerve growth factor by human pulmonary epithelial cells: role in airway inflammatory diseases. Eur J Pharmacol 2001: 424;159-162.

132. Freund V, Frossard N. Expression of nerve growth factor in the airways and its possible role in asthma. Prog Brain Res 2004:146;335-346.

133. Bánvölgyi Á, Pozsgai G, Brain SD, et al. Mustard oil induces a transient receptor potential vanilloid 1 receptorindependent neurogenic inflammation and a non-neurogenic cellular inflammatory component in mice. Neuroscience 2004: 125;449-459.

134. Barker JS, Wu Z, Hunter DD, et al. Ozone exposure initiates a sequential signaling cascade in airways involving interleukin-1beta release, nerve growth factor secretion, and substance P upregulation. J Toxicol Environ Health A 2015:78;397-407.

135. Bautista DM, Pellegrino M, Tsunozaki M. TRPA1: a gatekeeper for inflammation. Annu Rev Physiol 2013:75;181200.

136. Wu Z-X, Dey RD. Nerve growth factor-enhanced airway responsiveness involves substance $\mathrm{P}$ in ferret intrinsic airway neurons. Am J Physiol Lung Cell Mol Physiol 2006: 291;L111-L118.

137. Vincent MJ, Bernstein JA, Basketter D, et al. Chemicalinduced asthma and the role of clinical, toxicological, exposure and epidemiological research in regulatory and hazard characterization approaches. Regul Toxicol Pharmacol 2017:90;126-132.

138. Bernstein JA, Singh U. Neural abnormalities in nonallergic rhinitis. Curr Allergy Asthma Rep 2015:15;18.

139. Baraldo S, Turato G, Bazzan E, et al. Noneosinophilic asthma in children: relation with airway remodelling. Eur Respir J 2011:38;575-583.

140. Mapp CE, Saetta M, Maestrelli P, et al. Mechanisms and pathology of occupational asthma. Eur Respir J 1994:7; 544-554.

141. Shahana S, Björnsson E, Lúdvíksdóttir D, et al. Ultrastructure of bronchial biopsies from patients with allergic and non-allergic asthma. Respir Med 2005:99;429-443.

142. Takeda N, Maghni K, Daigle S, et al. Long-term pathologic consequences of acute irritant-induced asthma. J Allergy Clin Immunol 2009:124;975.e1-981.e1.

143. Simpson JL, Scott R, Boyle MJ, et al. Inflammatory subtypes in asthma: assessment and identification using induced sputum. Respirology 2006:11;54-61.

144. Fahy JV, Kim KW, Liu J, et al. Prominent neutrophilic inflammation in sputum from subjects with asthma exacerbation. J Allergy Clin Immunol 1995:95;843-852.

145. Hoffmann F, Ender F, Schmudde I, et al. Origin, localization, and immunoregulatory properties of pulmonary phagocytes in allergic asthma. Front Immunol 2016:7. DOI: 10.3389/ fimmu.2016.00107. 
146. Wisnewski AV, Liu J, Redlich CA. Connecting glutathione with immune responses to occupational methylene diphenyl diisocyanate exposure. Chem Biol Interact 2013: 205;38-45.

147. OECD. The Adverse Outcome Pathway for Skin Sensitisation Initiated by Covalent Binding to Proteins, Part I: Scientific Evidence. Paris: Environmental Directorate, Organization for Economic Cooperation and Development (OECD); 2012.

148. Larson SD, Schelegle ES, Walby WF, et al. Postnatal remodeling of the neural components of the epithelialmesenchymal trophic unit in the proximal airways of infant rhesus monkeys exposed to ozone and allergen. Toxicol Appl Pharmacol 2004:194;211-220.

149. Wu Z-X, Hunter DD, Kish VL, et al. Prenatal and early, but not late, postnatal exposure of mice to sidestream tobacco smoke increases airway hyperresponsiveness later in life. Environ Health Perspect 2009:117;1434-1440.

150. Yu M, Zheng X, Peake J, et al. Perinatal environmental tobacco smoke exposure alters the immune response and airway innervation in infant primates. J Allergy Clin Immunol 2008:122;640-647.

151. Groneberg DA, Niimi A, Dinh QT, et al. Increased expression of transient receptor potential vanilloid-1 in airway nerves of chronic cough. Am J Respir Crit Care Med 2004:170;1276-1280.

152. Lee S, Kim M, Shin C, et al. Substance P-immunoreactive nerves in endobronchial biopsies in cough-variant and classic asthma. Respiration 2003:70;49-53.

153. Hoyle GW, Graham RM, Finkelstein JB, et al. Hyperinnervation of the airways in transgenic mice overexpressing nerve growth factor. Am J Respir Cell Mol Biol 1998: $18 ; 149-157$.

154. Nassenstein C, Kutschker J, Tumes D, et al. Neuro-immune interaction in allergic asthma: role of neurotrophins. Biochem Soc Trans 2006:34;591-593.

155. Olgart Hoglund C, de Blay F, Oster J-P, et al. Nerve growth factor levels and localisation in human asthmatic bronchi. Eur Respir J 2002:20;1110-1116.

156. Hatano N, Itoh Y, Suzuki H, et al. Hypoxia-inducible factor- $1 \alpha(H I F 1 \alpha)$ switches on transient receptor potential ankyrin repeat 1 (TRPA1) gene expression via a hypoxia response element-like motif to modulate cytokine release. J Biol Chem 2012:287;31962-31972.

157. Wang H, Zhang R, Bridle KR, et al. Two-photon dual imaging platform for in vivo monitoring cellular oxidative stress in liver injury. Sci Rep 2017:7; srep45374.

158. Ayala A, Muñoz MF, Argüelles S. Lipid peroxidation: production, metabolism, and signaling mechanisms of malondialdehyde and 4-hydroxy-2-nonenal. Oxid Med Cell Longev 2014:2014;360438.

159. Fulcher ML, Randell SH. Human nasal and tracheobronchial respiratory epithelial cell culture. Methods Mol Biol 2013:945;109-121.
160. Potera C. More human, more humane: a new approach for testing airborne pollutants. Environ Health Perspect 2007: 115;A148-A151.

161. Eskes C, Hofmann M. Overview on current status of alternative methods and testing approaches for skin irritation testing. In: Alternatives for Dermal Toxicity Testing. C Eskes, E van Vliet, H Maibach (eds); pp. 3-23. Cham: Springer; 2017.

162. Matsuda S, Hisama M, Shibayama $\mathrm{H}$, et al. In vitro eye irritancy test of lauryl derivatives using the reconstructed rabbit corneal epithelium model. Toxicol In Vitro 2009:23; $555-560$.

163. Kreda SM, Okada SF, van Heusden CA, et al. Coordinated release of nucleotides and mucin from human airway epithelial Calu-3 cells. J Physiol 2007:584;245-259.

164. NIOSH. Qualitative Risk Characterization and Management of Occupational Hazards: Control Banding (CB): A Literature Review and Critical Analysis. Cincinnati, $\mathrm{OH}$ : U.S. Department of Health and Human Services, Public Health Service, Centers for Disease Control and Prevention, National Institute for Occupational Safety and Health, DHHS (NIOSH); 2009.

165. Hudnell HK, Otto DA, House DE, et al. Exposure of humans to a volatile organic mixture. II. Sensory. Arch Environ Health 1992:47;31-38.

166. Yang K, Han X. Lipidomics: techniques, applications, and outcomes related to biomedical sciences. Trends Biochem Sci 2016:41;954-969.

167. Shao J, Katika MR, Schmeits PCJ, et al. Toxicogenomicsbased identification of mechanisms for direct immunotoxicity. Toxicol Sci 2013:135;328-346.

168. Pezzulo AA, Starner TD, Scheetz TE, et al. The air-liquid interface and use of primary cell cultures are important to recapitulate the transcriptional profile of in vivo airway epithelia. Am J Physiol Lung Cell Mol Physiol 2011:300; L25-L31.

169. Esch EW, Bahinski A, Huh D. Organs-on-chips at the frontiers of drug discovery. Nat Rev Drug Discov 2015:14; 248-260.

170. McKim JM. Building a tiered approach to in vitro predictive toxicity screening: a focus on assays with in vivo relevance. Comb Chem High Throughput Screen 2010:13; 188-206.

Address correspondence to: Dr. Lynne T. Haber

Kettering Lab Complex Department of Environmental Health University of Cincinnati College of Medicine 160 Panzeca Way Cincinnati, $\mathrm{OH}$ 45267-0056

E-mail: lynne.haber@uc.edu 